\title{
The distribution and presence of versicular-arbuscular mycorrhiza fungi in rhizosphere soil of Da Xanh pummelo in Ba Ria Vung Tau province
}

\author{
Huong N. D. Thai ${ }^{*}$, Linh T. M. Nguyen, \& Duong T. T. Pham \\ Faculty of Agronomy, Nong Lam University, Ho Chi Minh City, Vietnam
}

\begin{abstract}
ARTICLE INFO
Research Paper

Received: February 23, 2021

Revised: April 02, 2021

Accepted: April 16, 2021

Keywords

Acaulospora

Glomus

Mycorrhiza distribution

Pummelo

Soil depth

\section{* Corresponding author}

Thai Nguyen Diem Huong Email: diemhuong_tn@hcmuaf.edu.vn soil.

ABSTRACT

The study was carried out to determine the distribution and presence of versicular-arbuscular mycorrhiza (VAM) fungi in rhizosphere soil and roots of Da Xanh pummelo in Phu My town, Ba Ria Vung Tau province. The rhizosphere soil and root samples were collected from 6 - 7 years old pummelo of two main soil types, on two soil layers at depths of $0-20 \mathrm{~cm}$ and $20-40 \mathrm{~cm}$, at $2 / 3$ and the edge of canopy. The results showed that the presence of VAM spore density was higher in red basaltic soil (ferralsols) than black soil (luvisols), and common exist on the topsoil layer $(0-20 \mathrm{~cm})$ as well as the edge of canopy. Glomus and Acaulospora were two most abundant genera in survey areas, and the proportion of mycorrhizal spores ranged from $53.18 \pm 2.59 \%$ to 58.54 \pm 0.46 and from $23.68 \pm 2.96 \%$ to $29.33 \pm 0.64 \%$, respectively. Increasing the soil depth negatively affected on spore density of VAM fungi. The VAM fungi composition aslo changed with soil depth. The percentage of root colonization by VAM fungi ranged from $56.20 \pm 3.11 \%$ to $62.00 \pm 3.37 \%$, and the highest percentage of root colonization by VAM fungi was detected in red basaltic
\end{abstract}

Cited as: Thai, H. N. D, Nguyen, L. T. M, \& Pham, D. T. T. (2021). The distribution and presence of versicular-arbuscular mycorrhiza fungi in rhizosphere soil of Da Xanh pummelo in Ba Ria Vung Tau province. The Journal of Agriculture and Development 20(2), 10-16. 


\title{
Sự phân bố và hiện diện của nấm rễ nội cộng sinh (Vesicular Arbuscular Mycorrhyza) trong vùng đất trồng bưởi Da Xanh tại Bà Rịa Vũng Tàu
}

\author{
Thái Nguyễn Diễm Hương*, Nguyễn Thị Mỹ Linh \& Phạm Thị Thuỳ Dương \\ Khoa Nông Học, Trường Đại Học Nông Lâm TP.HCM, TP. Hồ Chí Minh
}

\author{
THÔNG TIN BÀI BÁO \\ Bài báo khoa học \\ Ngày nhận: 23/02/2021 \\ Ngày chỉnh sưa: 02/04/2021 \\ Ngày chấp nhận: 16/04/2021 \\ Từ khóa \\ Acaulospora \\ Bưởi \\ Độ sâu tầng đất \\ Glomus \\ Sự phân bố nấm nội cộng sinh \\ *Tác giả liên hệ \\ Thái Nguyễn Diễm Hương \\ Email: diemhuong_tn@hcmuaf.edu.vn
}

\section{TÓM TẮT}

Nghiên cứu được thực hiện nhằm xác định sự phân bố và hiện diện của nấm nội cộng sinh VAM (Versicular Arbuscular Mycorrhiza) trong vùng đất quanh rễ và rễ bưởi Da Xanh tại Phú Mỹ, Bà Rịa Vũng Tàu. Các mẫu đất và rễ được thu thập trên các vườn bưởi 6 - 7 năm tuổi, trồng trên 2 nền đất phổ biến tại địa phương, ở 2 tầng đất $0-20 \mathrm{~cm}$ và $20-40 \mathrm{~cm}$, tại $2 / 3$ tán và mép tán. Kết quả cho thấy nấm VAM hiện diện trên nền đất đỏ bazan với mật số bào tử cao hơn trong đất đen, tập trung chủ yếu ở tầng đất mặt $(0-20 \mathrm{~cm})$ và ở mép tán. Chi Glomus và Acaulospora là 2 chi chiếm ưu thế với tỉ lệ dao động lần lượt trong khoảng từ $53,18 \pm 2,59 \%$ đến $58,54 \pm 0,46 \%$ và $23,68 \pm$ $2,96 \%$ đến $29,33 \pm 0,64 \%$. Càng tăng độ sâu tầng đất, mật số bào tử nấm VAM càng giảm, thành phần các chi nấm cộng sinh cũng thay đổi. Tỉ lệ rễ có sự cộng sinh dao động từ 56,20 \pm $3,11 \%$ đến $62,00 \pm 3,37 \%$, cao nhất trên đất đỏ.

\section{1. Đặt Vấn Đề}

Nấm cộng sinh Vesicular Arbuscular Mycorrhiza (VAM) là một dạng cộng sinh giữa thực vật bậc cao và nấm. Gần $90 \%$ các loài cây trồng trên trái đất có sự tồn tại của nấm cộng sinh (Gadkar \& ctv., 2001). Sự có mặt của nấm cộng sinh trong vùng rễ cây trồng giúp cây trồng tăng tỉ lệ sống cây con, tăng khả năng sinh trưởng và số hoa. Wu \& ctv. (2011) đã báo cáo rằng việc chủng nấm cộng sinh vào cây họ cam quýt đã làm tăng số lượng rễ, chiều dài rễ và thể tích rễ, nhờ đó tăng khả năng hút nước và dinh dưỡng cho cây trồng. Với những lợi ích của nấm rễ cộng sinh như vậy, việc nghiên cứu ứng dụng nấm rễ nội cộng sinh trong nông nghiệp có vai trò quan trọng trong việc duy trì một hệ sinh thái ổn định và một nền nông nghiệp bền vững (Wang \& ctv., 2012), đặc biệt trong điều kiện bất lợi và tình hình khí hậu diễn biến phức tạp như hiện nay.

Bà Rịa Vũng Tàu có nhiều chủng loại cây ăn trái, trong đó có bưởi Da Xanh. Theo thống kê của BRVT CPPPS (2018), thị xã Phú Mỹ có diện tích trồng bưởi Da Xanh lớn nhất trong toàn tỉnh (chiếm gần $50 \%$ diện tích trồng bưởi Da Xanh của tỉnh), tập trung chủ yếu tại xã Sông Xoài và phường Hắc Dịch.

Để nâng cao chất lượng và xây dựng một vùng bưởi Da Xanh an toàn và bền vững, việc nghiên cứu sử dụng các chế phẩm sinh học là việc làm cần thiết, trong đó, nghiên cứu và ứng dụng nấm cộng sinh trong canh tác cây trồng là một trong những hướng cần được quan tâm. Vì vậy, nghiên cứu đã được thực hiện để xác định sự phân bố và hiện diện của những chủng nấm cộng sinh có trong vùng rễ và những nền đất trồng bưởi $\mathrm{Da}$ Xanh chủ yếu tại Phú Mỹ, Bà Rịa Vũng Tàu, làm nền tảng cho những nghiên cứu tiếp theo. 
Bảng 1. Thông tin mẫu đất và rễ thu thập tại Phú Mỹ, Bà Rịa Vũng Tàu

\begin{tabular}{ccccc}
\hline STT & Kí hiệu mẫu & Loại đất & Tuổi cây (tuổi) & Địa điểm thu thập \\
\hline 1 & SX1 & Đỏ bazan & 6 & Sông Xoài \\
2 & SX2 & Đỏ bazan & 6 & Sông Xoài \\
3 & SX3 & Đen & 6 & Sông Xoài \\
4 & SX4 & Đen & 7 & Sông Xoài \\
5 & SX5 & Đen & 6 & Sông Xoài \\
6 & HD1 & Đỏ bazan & 6 & Hắc Dịch \\
7 & HD2 & Đỏ bazan & 6 & Hắc Dịch \\
8 & HD3 & Đỏ bazan & 7 & Hắc Dịch \\
9 & HD4 & Đen & 6 & Hắc Dịch \\
10 & HD5 & Đen & 6 & Hắc Dịch \\
\hline
\end{tabular}

\section{Vật Liệu và Phương Pháp Nghiên Cứu}

\subsection{Vật liệu}

Mẫu đất và mẫu rễ thu thập tại vườn bưởi $\mathrm{Da}$ Xanh trên hai nền đất trồng bưởi phổ biến tại địa phương. Cây đang trong giai đoạn nuôi trái (giai đoạn 100 - 130 ngày sau đậu trái), khoẻ mạnh, 6 - 7 năm tuổi, thuộc xã Sông Xoài và phường Hắc Dịch, thị xã Phú Mỹ, tỉnh Bà Rịa Vũng Tàu. Thông tin chi tiết được trình bày trong Bảng 1.

Một số hoá chất và dụng cụ sử dụng trong nghiên cứu:

- Hoá chất: Đường Sucrose, acid lactic, glycerol, polyvinyl alcohol, hydrogen peroxide, amoniac, acid clohydric, chloral hydrate, iodine, trypan blue, acid acetic, kali hydroxit, potassium dichromate, acid sulfuric đậm đặc, acid phosphoric đậm đặc, muối morh và một số hoá chất khác.

- Thiết bị và dụng cụ: kính hiển vi Olympus (Model CX21FS1), lame, đĩa petri, giấy lọc, rây $50-1000 \mu \mathrm{m}$, cốc thủy tinh $10 \mathrm{~mL}$ và $1000 \mathrm{~mL}$, pipet, máy ly tâm và một số thiết bị khác.

\subsection{Phương pháp nghiên cứu}

Chọn ngẫu nhiên 10 hộ canh tác bưởi Da Xanh trên các nền đất trồng bưởi phổ biến tại Phú Mỹ, Bà Rịa Vũng Tàu, diện tích trồng lớn hơn 1.000 $\mathrm{m}^{2}$, cây ở giai đoạn cho trái ổn định (6 - 7 năm tuổi), không bón phân cách thời điểm thu mẫu 7 ngày. Tiến hành thu thập mẫu ở 2 tầng đất: 0 $20 \mathrm{~cm}, 20-40 \mathrm{~cm}$; ở vị trí $2 / 3$ tán và mép tán.

Phương pháp lấy mẫu: dựa theo TCVN5297 1995. Trên mỗi vườn thu mẫu, chọn ngẫu nhiên 5 điểm trong vườn theo đường chéo góc, mỗi điểm chọn 1 cây, mỗi cây lấy ở 4 vị trí ở 4 hướng khác nhau, mỗi vị trí lấy mẫu tại 2 tầng đất. Khi thu mẫu, loại bỏ lớp đất mặt 0 - 2 cm để loại trừ xác bã thực vật, dùng xẻng đã khử trùng bằng cồn đào lấy đất ở độ sâu $0-20 \mathrm{~cm}$ và $20-40 \mathrm{~cm}$, ở vị trí $2 / 3$ tán và mép tán. Mẫu được đựng vào bao, dán nhãn kí hiệu vùng đất, địa điểm, vị trí, tầng đất lấy mẫu và mang về phòng thí nghiệm ngay sau khi thu.

Phương pháp xử lý mẫu: Mẫu rễ được tách khỏi đất, rửa sạch, loại bỏ các rễ già, hư hỏng, sau đó, cắt rễ thành từng đoạn dài $1 \mathrm{~cm}$ và tiến hành nhuộm rễ. Đối với mẫu đất, loại bỏ xác bã thực vật, tiến hành phân lập và đếm số lượng bào tử nấm cộng sinh có trong mẫu thu thập.

Chỉ tiêu theo dõi:

- Nấm cộng sinh:

Mật số bào tử nấm cộng sinh (bào tử/100 g đất): đếm số lượng bào tử có trong $100 \mathrm{~g}$ đất trên kính hiển vi. Việc phân lập bào tử nấm cộng sinh theo TCVN 12560 - 1:2018 bằng kỹ thuật sàng ướt ly tâm nổi.

$\%$ chi trong mẫu (\%): đếm số lượng từng chi và tính tỉ lệ \% mỗi chi có trong mẫu. Việc định danh được thực hiện theo các tiêu chí của INVAM.

Tỉ lệ đoạn rễ có nấm cộng sinh $(\%)$ : cắt rễ thành từng đoạn có chiều dài $1 \mathrm{~cm}$, chọn ngẫu nhiên 20 đoạn rễ/mẫu, quan sát dưới kính hiển vi sau khi nhuộm bằng trypan blue. Ghi nhận tỉ lệ xâm nhiễm và tính tỉ lệ đoạn rễ có cộng sinh.

Tỉ lệ đoạn rễ có nấm cộng sinh $(\%)=$ (số đoạn rễ có nấm cộng sinh/tổng số đoạn rễ quan sát) x 100.

\section{- Đất:}

Thành phần cơ giới: Theo TCVN 8567:2010. $\mathrm{pH}_{\mathrm{H}_{2} \mathrm{O}}$ : Đo bằng máy đo $\mathrm{pH}$.

Hàm lượng chất hữu cơ (\%): Theo phương pháp Tyurin. 
Bảng 2. Một số tính chất lý hoá của đất trồng bưởi Da Xanh tại Phú Mỹ, Bà Rịa Vũng Tàu

\begin{tabular}{|c|c|c|c|c|c|c|}
\hline \multirow{2}{*}{ Loại đất } & \multirow{2}{*}{ Vị trí lấy mẫu } & \multicolumn{3}{|c|}{ Thành phần cơ giới đất } & \multirow{2}{*}{$\begin{array}{c}\mathrm{pH}_{\text {nước }} \\
(1: 5)\end{array}$} & \multirow{2}{*}{$\begin{array}{c}\text { Hàm lượng } \\
\text { chất hữu cơ }(\%)\end{array}$} \\
\hline & & Sét $(\%)$ & Thịt $(\%)$ & Cát $(\%)$ & & \\
\hline \multirow{2}{*}{ Đen } & $2 / 3$ tán & 59,33 & 10,00 & 30,67 & 4,52 & 3,29 \\
\hline & Mép tán & 63,33 & 9,33 & 27,33 & 4,70 & 3,69 \\
\hline \multirow{2}{*}{ Đỏ bazan } & 2/3 tán & 63,33 & 8,67 & 28,00 & 4,65 & 3,48 \\
\hline & Mép tán & 67,33 & 8,67 & 24,00 & 4,84 & 3,94 \\
\hline
\end{tabular}

Bảng 3. Sự phân bố của bào tử nấm cộng sinh trên các nền đất và độ sâu khác nhau

\begin{tabular}{|c|c|c|c|c|}
\hline \multirow{2}{*}{ Chỉ tiêu } & \multirow{2}{*}{ Loại đất } & \multicolumn{2}{|c|}{ Tầng đất } & \multirow{2}{*}{ t-test } \\
\hline & & $0-20 \mathrm{~cm}$ & $20-40 \mathrm{~cm}$ & \\
\hline \multirow[b]{2}{*}{ Mật số bào tử (bào tử/100g đất khô kiệt) } & Đen & $149,05 \pm 4,49$ & $53,91 \pm 1,77$ & ** \\
\hline & $\begin{array}{l}\text { Đỏ bazan } \\
\text { t-test }\end{array}$ & $\underset{* *}{168,66 \underset{ }{ \pm} 10,17}$ & $\underset{* *}{57,97} \underset{*}{ \pm} 1,70$ & $* *$ \\
\hline \multirow[b]{2}{*}{ \% bào tử Glomus (\%) } & Đen & $57,96 \pm 0,39$ & $53,18 \pm 2,59$ & $* *$ \\
\hline & $\begin{array}{l}\text { Đỏ bazan } \\
\text { t-test }\end{array}$ & $\begin{array}{c}58,54 \pm 0,46 \\
\mathrm{~ns}\end{array}$ & $\begin{array}{c}53,92 \pm 2,48 \\
\mathrm{~ns}\end{array}$ & $* *$ \\
\hline \multirow[b]{2}{*}{ \% bào tử Acaulospora (\%) } & Đen & $29,33 \pm 0,64$ & $24,98 \pm 3,06$ & $* *$ \\
\hline & $\begin{array}{l}\text { Đỏ bazan } \\
\text { t-test }\end{array}$ & $\begin{array}{c}29,28 \pm 0,56 \\
\mathrm{~ns}\end{array}$ & $\begin{array}{c}23,68 \pm 2,96 \\
\mathrm{~ns}\end{array}$ & $* *$ \\
\hline \multirow[b]{2}{*}{ \% bào tử chi chưa định danh được $(\%)$} & Đen & $12,71 \pm 0,54$ & $21,84 \pm 3,29$ & $* *$ \\
\hline & $\begin{array}{l}\text { Đỏ bazan } \\
\text { t-test }\end{array}$ & $\begin{array}{c}12,18 \pm 0,53 \\
\mathrm{~ns}\end{array}$ & $\begin{array}{c}22,41 \pm 2,97 \\
\mathrm{~ns}\end{array}$ & $* *$ \\
\hline
\end{tabular}

\pm khoảng tin cậy ở mức 95\%; **: Sự khác biệt rất có ý nghĩa thống kê; ${ }^{\text {ns }}$ : Sự khác biệt không có ý nghĩa thống kê.

Phương pháp xử lý số liệu: Các số liệu thu thập được tổng hợp, xử lý và so sánh t-test bằng phần mềm Excel.

\section{Kết Quả và Thảo Luận}

\section{1. Đặc tính lý hoá của đất trồng bưởi $\mathrm{Da}$ Xanh}

Những đặc điểm của đất có ảnh hưởng một cách rõ ràng đến cả cây trồng và nấm cộng sinh nên việc nghiên cứu về VAM cần xem xét đến yếu tố thổ nhưỡng cũng như cây trồng và nấm (Kapoor \& ctv., 2002). Tại Phú Mỹ, Bà Rịa Vũng Tàu, các nông hộ trồng bưởi chủ yếu trên hai nền đất: đất đen và đất đỏ bazan. Kết quả Bảng 2 cho thấy, mẫu đất tại các điểm khảo sát có sa cấu sét (với tỉ lệ sét cao hơn 50\%) (USDA, 1960), trong đó đất bazan có tỉ lệ sét cao hơn $60 \%$. Đồng thời, các mẫu đất có $\mathrm{pH}_{\mathrm{H}_{2} \mathrm{O}}(1: 5)$ ở mức chua rất nhiều (Slavich \& Petterson, 1993), dao động trong khoảng 4,52 - 4,84. Ở mức pH này, lân và một số nguyên tố khác dễ bị cố định, gây ảnh hưởng một phần đến sự phân bố và hiện diện của các chi và loài nấm cộng sinh. Hàm lượng chất hữu cơ ở mức trung bình (Rayment \& Lyons,
2011), dao động từ 3,29 - 3,94\%. Kết quả cho thấy, $\mathrm{pH}$ và hàm lượng chất hữu cơ ở phần mép tán có xu hướng cao hơn ở $2 / 3$ tán. Điều này có thể giải thích là do tập quán canh tác của nông dân địa phương, đặc biệt là cách bón phân nên ảnh hưởng đến tính chất hoá học của đất. Đa số nông dân trồng bưởi tại Phú Mỹ, Bà Rịa Vũng Tàu bón phân hoá học ở vị trí khoảng $2 / 3$ tán. Việc bón một số loại phân hoá học, đặc biệt là super lân, kali sunphat sẽ khiến đất chua hơn.

\subsection{Sự phân bố của bào tử nấm cộng sinh trên các nền đất khác nhau}

Trên 2 nền đất trồng bưởi $\mathrm{Da}$ Xanh phổ biến tại Phú Mỹ, Bà Rịa Vũng Tàu, kết quả khảo sát cho thấy có sự hiện diện của VAM với nhiều chi khác nhau, trong đó có 2 chi định danh được là Glomus và Acaulospora. Ở các tầng đất khác nhau, mật số bào tử nấm cộng sinh, tỉ lệ \% của các chi hiện diện trong đất cũng khác nhau và khác biệt rất có ý nghĩa về mặt thống kê (Bảng 3). Trên cùng một tầng đất, ở hai loại đất khác nhau, có sự khác biệt rất có ý nghĩa về mật số bào tử nhưng tỉ lệ \% của các chi hiện diện trong đất khác biệt không có ý nghĩa về mặt thống kê khi so sánh t-test. Đất có 
hàm lượng sét, $\mathrm{pH}$ và chất hữu cơ cao hơn thì mật số bào tử VAM cũng có xu hướng tăng. Kết quả này phù hợp với kết luận của Day \& ctv. (1987) và Johnson \& ctv. (1991). Đặc biệt trên nền đất giàu hữu cơ, sự phân nhánh và phát triển của sợi nấm sẽ được kích thích khi có sự cạnh tranh với các vi sinh vật khác (Joner \& Jakobsen, 1995). Do đó, mật số bào tử VAM trong đất đỏ bazan cao hơn mật số bào tử VAM trong đất đen, khác biệt rất có ý nghĩa về mặt thống kê. Mặt khác, Bảng 3 cũng cho thấy nấm VAM hiện diện chủ yếu trên tầng đất mặt $(0-20 \mathrm{~cm})$ với mật số khá cao và giảm mạnh ở tầng $20-40 \mathrm{~cm}$. Điều này cho thấy, độ sâu của đất càng tăng, mật số bào tử nấm VAM càng giảm. Kết quả này phù hợp với nghiên cứu của Cuenca \& Lovera (2010), Shukla \& ctv. (2013), Nguyen \& ctv. (2017). Bởi khi độ sâu đất càng tăng, lượng chất hữu cơ, hàm lượng oxy sẽ càng giảm, và các rễ tơ - nơi nấm rễ có thể cộng sinh tập trung chủ yếu ở lớp đất mặt.

Trong các chi nấm VAM hiện diện trong đất trồng bưởi Da Xanh tại Phú Mỹ, Bà Rịa Vũng Tàu, chi Glomus chiếm ưu thế nhất (trên $50 \%$ ). Đây cũng là chi nấm hiện diện chủ yếu trong đất trồng cây có múi theo kết luận của Davies \& Albrigo (1994) và Fidelibus \& ctv. (2000). Một vài loài trong chi Glomus phổ biến trong đất trung tính hoặc kiềm nhưng một số ít lại hiện diện trong đất chua trong khi các loài thuộc chi Acaulospora lại thường tìm thấy trên đất chua (Rupam \& ctv., 2002). Chính vì vậy, kết quả khảo sát trên vùng đất trồng bưởi Da Xanh tại Phú Mỹ cho thấy, bên cạnh chi Glomus, chi Acaulospora cũng khá phổ biến. Chi Acaulospora và chi Glomus cũng là hai trong những chi phổ biến nhất trên đất trồng cam ở Nghệ An (Nguyen \& ctv., 2012) hay đất trồng cam quýt ở miền Nam Trung Quốc (Wang \& ctv., 2012).

Bảng 3 cũng cho thấy sự phân bố và hiện diện của các chi nấm thay đổi theo độ sâu tầng đất, khác biệt rất có ý nghĩa về mặt thống kê khi so sánh t-test. Kết quả này cũng phù hợp với nghiên cứu của Shukla \& ctv. (2013). Theo Oehl \& ctv. (2005), có thể có một vài loài VAM khá phổ biến, có mặt ở các độ sâu khác nhau của đất nhưng cũng có một vài loài chỉ hiện diện ở độ sâu đặc biệt và rất khác biệt so với những loài VAM có trong tầng đất mặt. Có lẽ chính vì vậy mà những chi khác (chưa định danh được) hiện diện trong tầng đất trồng bưởi $\mathrm{Da}$ Xanh tại Phú Mỹ ở độ sâu 20 - $40 \mathrm{~cm}$ với tỉ lệ cao hơn so với tầng 0 - 20 $\mathrm{cm}$.

\subsection{Sự phân bố của bào tử nấm cộng sinh ở các vị trí lấy mẫu khác nhau}

Bảng 4 cho thấy trên đất trồng bưởi Da Xanh tại Phú Mỹ, Bà Rịa Vũng Tàu, ở các tầng đất và vị trí lấy mẫu khác nhau, mật số bào tử nấm VAM nói chung và các chi Glomus, Acaulospora nói riêng khác biệt rất có ý nghĩa về mặt thống kê. Cụ thể, mật số bào tử ở tầng đất mặt $(0-$ $20 \mathrm{~cm}$ ) cao hơn lượng bào tử thu thập ở tầng 20 - $40 \mathrm{~cm}$ bởi việc sản sinh bào tử tập trung chủ yếu ở lớp đất mặt (Oehl \& ctv., 2005; Cuenca \& Lovera, 2010) và có thể cộng sinh với phần lớn rễ hút hiện diện ở tầng canh tác. Nấm VAM phụ thuộc hoàn toàn vào nguồn cacbon của cây ký chủ, vì vậy, sự phân bố của bào tử VAM có liên quan đến sự phân bố rễ trong đất. Kết quả cũng cho thấy bào tử chi Glomus và Acaulospora hiện diện với mật số khá cao, đặc biệt là trên tầng đất mặt. Có lẽ do đây là hai chi cần ít thời gian để hình thành bào tử hơn loài của các chi khác (Wang \& Jiang, 2015). Hơn nữa, kết quả cũng chỉ ra rằng, bào tử VAM tập trung nhiều ở phần mép tán (nhiều hơn so với $2 / 3$ tán) ở tất cả các tầng đất. Điều này có thể lý giải là do ở mép tán, $\mathrm{pH}$ và hàm lượng chất hữu cơ cao hơn (Bảng 2 ) nên nấm cộng sinh hiện diện chủ yếu tại vị trí này (Joner \& Jakobsen, 1995; He \& ctv., 2002). Bên cạnh đó, theo quan sát thực địa, một lượng lớn rễ hút phân bố chủ yếu theo hình chiếu tán cây, tạo điều kiện cho nấm cộng sinh xâm nhập và phát triển. Riêng đối với chi Acaulospora, mật số bào tử trong tầng đất mặt $(0-20 \mathrm{~cm})$ ở mép tán và 2/3 tán là như nhau, khác biệt không có ý nghĩa về mặt thống kê. Tương tự, ở tầng sâu hơn $(20$ $40 \mathrm{~cm}$ ), mật số bào tử chưa định danh được cũng không phụ thuộc vào vị trí lấy mẫu.

\subsection{Sự phân bố của nấm cộng $\sinh$ trong rễ}

Lợi ích mà nấm VAM mang lại chỉ khi có sự cộng sinh với rễ (Solaiman \& Hirata, 1996). Kết quả cho thấy nấm VAM cộng sinh trong rễ bưởi Da Xanh trồng tại Phú Mỹ, Bà Rịa Vũng Tàu với tî lệ khác nhau. Có khoảng 53 - 65\% đoạn rễ khảo sát có sự cộng sinh. Theo thang phân loại của Zangaro \& ctv. (2002), kết quả này ở mức trung bình đến cao. Theo khảo sát t-test, tỉ lệ đoạn rễ có nấm cộng sinh ở vị trí $2 / 3$ tán và mép tán khác biệt không có ý nghĩa về mặt thống kê trên cả hai nền đất (Bảng 5 ). Tuy nhiên, có sự khác biệt có ý nghĩa thống kê về tỉ lệ đoạn rễ bưởi Da Xanh có nấm cộng sinh trên 2 nền đất tại vị 
Bảng 4. Sự phân bố của bào tử nấm cộng sinh ở độ sâu và vị trí lấy mẫu khác nhau

\begin{tabular}{|c|c|c|c|c|c|}
\hline \multirow{2}{*}{ Chỉ tiêu } & \multirow{2}{*}{ Tầng đất } & \multicolumn{2}{|c|}{ Vị trí lấy mẫu } & \multirow{2}{*}{ Trung bình } & \multirow{2}{*}{ t-test } \\
\hline & & $2 / 3$ tán & Mép tán & & \\
\hline \multirow[b]{2}{*}{$\begin{array}{l}\text { Mật số bào tử VAM } \\
\text { (bt/100 g đất khô kiệt) }\end{array}$} & $0-20 \mathrm{~cm}$ & $150,43 \pm 7,81$ & $167,29 \pm 8,17$ & $158,86 \pm 7,84$ & $* *$ \\
\hline & $\begin{array}{l}20-40 \mathrm{~cm} \\
\text { t-test }\end{array}$ & $\begin{array}{c}52,25 \underset{* *}{ \pm} 1,34 \\
* *\end{array}$ & $\begin{array}{c}59,62 \underset{* *}{ \pm} 1,64 \\
* *\end{array}$ & $55,94 \pm 1,30$ & $* *$ \\
\hline \multirow[b]{2}{*}{$\begin{array}{l}\text { Mật số bào tử Glomus } \\
\text { (bt/100 g đất khô kiệt) }\end{array}$} & $0-20 \mathrm{~cm}$ & $87,45 \pm 4,74$ & $97,62 \pm 4,62$ & $92,54 \pm 4,57$ & $* *$ \\
\hline & $\begin{array}{l}20-40 \mathrm{~cm} \\
\text { t-test }\end{array}$ & $\begin{array}{c}28,02 \pm 1,59 \\
* *\end{array}$ & $\underset{* *}{31,87 \pm 1,60}$ & $29,94 \pm 1,25$ & $* *$ \\
\hline \multirow{2}{*}{$\begin{array}{l}\text { Mật số bào tử Acaulospora } \\
\text { (bt/100 g đất khô kiệt) }\end{array}$} & $0-20 \mathrm{~cm}$ & $44,84 \pm 2,74$ & $48,51 \pm 2,91$ & $46,67 \pm 2,74$ & ns \\
\hline & $\begin{array}{l}20-40 \mathrm{~cm} \\
\text { t-test }\end{array}$ & $\begin{array}{c}11,99 \pm 1,51 \\
* *\end{array}$ & $\begin{array}{c}15,39 \pm 1,95 \\
* *\end{array}$ & $13,69 \pm 1,20$ & ** \\
\hline \multirow{2}{*}{$\begin{array}{l}\text { Mật số bào tử chi chưa } \\
\text { định danh được } \\
\text { (bt/100 g dất khô kiệt) }\end{array}$} & $0-20 \mathrm{~cm}$ & $18,14 \pm 0,89$ & $21,15 \pm 1,18$ & $19,65 \pm 0,92$ & $* *$ \\
\hline & $\begin{array}{l}20-40 \mathrm{~cm} \\
\text { t-test }\end{array}$ & $\underset{* *}{12,24 \underset{1,71}{ \pm}}$ & $\underset{* *}{12,37 \underset{1,81}{ \pm}}$ & $12,31 \pm 1,33$ & ns \\
\hline
\end{tabular}

\pm khoảng tin cậy ở mức $95 \%{ }^{* *}$ : Khác biệt rất có ý nghĩa thống kê; ${ }^{*}$ : Sự khác biệt có ý nghĩa thống kê; ${ }^{\text {ns }}$ : Sự khác biệt không có ý nghĩa thống kê.

trí $2 / 3$ tán. Điều này cho thấy vị trí $2 / 3$ hay mép tán, nấm VAM đều có thể cộng sinh trong rễ với tỉ lệ như nhau. Tỉ lệ này chỉ bị ảnh hưởng khi canh tác bưởi trên các nền đất khác nhau. Trên nền đất đỏ bazan, tî̉ lệ đoạn rễ bưởi có nấm cộng sinh cao hơn đoạn rễ bưởi thu thập trên nền đất đen. Nguyên nhân có thể do bào tử VAM ở nền đất này hiện diện với mật số cao hơn.

Bảng 5. Tỉ lệ (\%) đoạn rễ bưởi Da Xanh có nấm cộng sinh

\begin{tabular}{cccc}
\hline \multirow{2}{*}{ Loại đất } & \multicolumn{2}{c}{ Vị trí lấy mẫu } & \multirow{2}{*}{ t-test } \\
\cline { 2 - 3 } & $2 / 3$ tán & Mép tán & \\
\hline Đen & $56,20 \pm 3,11$ & $58,40 \pm 3,80$ & ns \\
Đỏ bazan & $62,00 \pm 3,37$ & $62,20 \pm 3,10$ & ns \\
t-test & $*$ & ns & \\
\hline
\end{tabular}

: \pm Khoảng tin cậy ở mức $95 \%$; ${ }^{*}$ : Sự khác biệt có ý nghĩa thống kê; ${ }^{\text {ns }}$ : Sự khác biệt không có ý nghĩa thống kê.

\section{Kết Luận}

Trên vùng đất trồng bưởi Da Xanh tại Phú Mỹ, Bà Rịa Vũng Tàu có sự hiện diện của VAM với 2 chi chính là Glomus và Acaulospora. Mật số bào tử VAM và tỉ lệ rễ có sự cộng sinh trên nền đất đỏ cao hơn trên đất đen, tập trung chủ yếu trên tầng đất mặt và ở vị trí mép tán. Độ sâu tầng canh tác càng cao, mật số bào tử càng giảm và thành phần các chi VAM cũng thay đổi.

\section{Tài Liệu Tham Khảo (References)}

BRVT CPPPS (Ba Ria Vung Tau Crop Production and Plant Protection Subdepartment). (2018). Fruit crops production status in Ba Ria Vung Tau (research report). Ba Ria Vung Tau Agriculture and Rural Development Department, Ba Ria Vung Tau, Vietnam.

Cuenca, G., \& Lovera, M. (2010). Seasonal variation and distribution at different soil depths of Arbuscular Mycorrhizal fungi spores in a tropical sclerophyllous shrubland. Botany 88(1), 54-64.

Davies, F. S., \& Albrigo, L. G. (1994). Citrus (Crop production science in horticulture) ( $1^{\text {st }}$ ed.). Oxford, UK: Oxford University Press.

Day, L. D., Sylvia, D. M., \& Collins, M. E. (1987). Interactions among vesicular arbuscular mycorrhizae, soil, and landscape position. Soil Science Society of America Journal 51(3), 635-639.

Fidelibus, M. W., Martin, C. A., Wright, G. C., \& Stutz, J. C. (2000). Effect of arbuscular mycorrhizal (AM) fungal communities on growth of 'Volkamer' lemon in continually moist or periodically dry soil. Scientia Horticulturae 84(1-2), 127-140.

Gadkar, V., David-Schwartz, R., Kunik, T., \& Kapulnik, Y. (2001). Arbuscular mycorrhizal fungal colonization. Factors involved in host recognition. Plant Physiology 127(4), 1493-1499.

He, X. L., Mouratov, S., \& Steinberger, Y. (2002). Spatial distribution and colonization of arbuscular mycorrhizal fungi under the canopies of desert halophytes. Arid Land Research and Management 16(2), 149-160.

Johnson, N. C., Zak, D. R., Tilman, D., \& Pfleger, F. L. (1991). Dynamics of vesicular-arbuscular mycorrhizal fungi during old field succession. Oecologia 86, 349358.

Joner, E. J., \& Jakobsen, I. (1995). Growth and extracellular phosphatase activity of arbuscular mycorrhizal hyphae as influenced by soil organic matter. Soil Biology and Biochemistry 27(9), 1153-1159. 
Kapoor, R., Giri, B., \& Mukerji, K. G. (2002). Soil factors in relation to distribution and occurrence of vesicular Arbuscular Mycorrhiza. In Mukerji, K. G., Manoharachary, C., \& Chamola, B. P. (Eds.). Techniques in mycorrhizal studies (51-85). Dordrecht, Germany: Springer.

Nguyen, L. T. K., Le, T. T., Nguyen, H. V., \& Nguyen, H. H. (2012). A study on Arbuscular Mycorrhiza diversity in soil and orange roots sampled from Quy Hop, Nghe An. Journal of Biology 34(4), 441-445.

Nguyen, T. T., Tran T. T. T., \& Nguyen, H. V. (2017). Distribution of Arbuscular Mycorrhiza fungi (AMF) spores in citrus orchards in Cao Phong district, Hoa Binh province. Journal of Science: Advanced Materials and Devices 33(1S), 235-242.

Rayment, G. E., \& Lyons, D. J. (2011). Soil chemical methods - Australasia. Collingwood, Australia: Csiropublishing.

Shukla, A., Vyas, D., \& Anuradh, J. (2013). Soil depth: an overriding factor for distribution of arbuscular mycorrhizal fungi. Journal of Soil Science and Plant $\mathrm{Nu}$ trition 13(1), 23-33.

Slavich, P. G., \& Petterson, G. H. (1993). Estimating the critical conductivity of saturated paste extracts from 1:5 soil: water suspensions and texture. Australian Journal of Soil Research 31(1), 73-81.

Solaiman, M. Z., \& Hirata, H. (1996). Effectiveness of arbuscular mycorrhizal colonization at nursery stage on growth and nutrition in wetland rice (Oryza sativa L) after transplanting under different soil fertility and water regimes. Soil Science and Plant Nutrition $42(3), 561-571$.
Oehl, F., Sieverding, E., Ineichen, K., Ris, E. A., Boller, T., \& Wiemken, A. (2005). Community structure of arbuscular mycorrhizal fungi at different soil depths in extensively managed agroecosystems. New Phytologist 165(1), 273-283.

Wang, M., \& Jiang, P. (2015). Colonization and diversity of AM fungi by morphological analysis on medicinal plants in Southeast China. The Scientific World Journal (ID 753842). https://doi.org/10.1155/2015/753842.

Wang, P., Zhang, J. J., Shu, B., \& Xia, R. X. (2012). Arbuscular mycorrhizal fungi associated with citrus orchards under different types of soil management, southern China. Plant Soil Environment 58, 302-308.

Wu, Q. S., Zou, Y. N., He, X. H., \& Luo, P. (2011). Arbuscular mycorrhizal fungi can alter some root characters and physiological status in trifoliate orange (Poncirus trifoliate L. Raf.) seedlings. Plant Growth Regulation $65,273-278$.

Zangaro, W., Nisizaki, S. M. A., Domingos, J. C. B., \& Nakano, E. M. (2002). Arbuscular mycorrhizal in native woody species of Tibagi River Basin, Paraná. Cerne 8(1), 077-087. 